\title{
Resveratrol Attenuates Both Small Bowel and Liver Changes in Obstructive Jaundice
}

\author{
Volkan Temi ${ }^{1}$, Erdem Okay ${ }^{1}$, Abdullah Güneş ${ }^{1}$, Turgay Şimşek ${ }^{1}$, Mustafa Çekmen², Ümit Bilgili², \\ Yeşim Gürbüz ${ }^{3}$
}

\begin{abstract}
${ }^{1}$ Department of General Surgery, Kocaeli University School of Medicine, Kocaeli, Turkey ${ }^{2}$ Department of Medical Biochemistry, Kocaeli University School of Medicine, Kocaeli, Turkey ${ }^{3}$ Department of Pathology, Kocaeli University School of Medicine, Kocaeli, Turkey
\end{abstract}

Background: It is well known that mucosal changes and alterations in liver function occur in the experimental obstructive jaundice model. Aims: We aimed to evaluate the effect of resveratrol on obstructive jaundice-induced changes in the small bowel mucosa and liver using ischaemia-modified albumin as a marker of oxidative damage.

Study Design: Animal experimentation.

Methods: The study used a rodent experimental model of obstructive jaundice, including a sham group (1), a control group (2), and a study group (3). Wistar albino rats were used. Jaundice was produced by ligation of the bile duct in Groups 2 and 3. In Group 3, resveratrol was administered intraperitoneally for 14 days.

Results: In terms of the structure and the size of the mucosal villi, significant thickening and blunting were detected in Group 2 compared with Group 1. These changes were significantly less noticeable in Group 3 compared with Group 2. Levels of ischaemia-modified albumin were significantly higher in Group 2 compared with those in Group 1, and they were significantly decreased in Group 3 compared with Group 2.

Conclusion: Resveratrol administration to obstructive jaundiced rats reduced the organic effects of obstructive jaundice on small bowel mucosa and liver oxidative stress. We believe that this reduction might attenuate bacterial translocation and systemic effects of secreted cytokines. (Balkan Med J 2014;31:95-99).

Key Words: Experimental, ischemia modified albumin, jaundice, obstructive, resveratrol
It is well known that biliary obstruction causes hepatocellular damage. Clinical and experimental studies on the mechanism of this damage indicate a crucial role for free oxygen radicals (FORs) (1-4). Natural defence mechanisms (antioxidant systems) are insufficient, due to the increased oxidative stress caused by the elevation in FORs. Thus, general antioxidant system insufficiency, particularly insufficiency in the glutathione oxidoreduction system (the major component of the cellular antioxidant system), occurs. Initially, levels of lipid peroxides that are formed by the oxidation of lipids and protein molecules increase. Following this, cell membranes are damaged, and this process progresses to apoptosis due to deterioration in mitochondrial respiration and DNA synthesis and repair $(1-3,5,6)$.

Antioxidants protect proteins, nucleic acids, and carbohydrates by preventing lipid peroxidation $(6,7)$. Resveratrol $(\mathrm{RV})$, which is found in black grapes and named chemically as $3,4^{\prime}, 5$ trihydroxystilbene and 3,4',5 stilbenetriol, is a polyphenolic phytoalexin with a flavonoid structure. It is synthesised by plants following traumatic injury or fungal attacks, and is recognised for its anti-inflammatory and antioxidant properties $(8,9)$.

Under acute ischemic conditions, FORs within the environment increase, and the metal-binding capacity of the N-terminal region of albumin decreases. This results in a measurable change in ischaemia-modified albumin (IMA) (10-12). Increased FORs play a crucial role in protein, nucleic acid, and lipid damage. The metal-binding sites of biological molecules such as albumin undergo structural changes. As a result of hypoxia, albumin binds to metal atoms oxidised by oxidising agents, particularly $\mathrm{OH}$ radicals, and the bound albumin continues to form IMA $(11,13)$.

The effects of obstructive jaundice on the intestinal mucosa are well known. It is associated with a reduction in the villus or total mucosal thickness, an increase in the villus width, and an increase in subepithelial edema, inflammation, and oxidative stress $(14,15)$. These changes have a crucial role in obstructive jaundice because they promote bacterial translocation and related events, as well as cytokines secreted by inflammatory cells (16-19). Although the effects of several 
products on the mucosal changes in the bowel have been evaluated in experimental models, there appear to be no studies of the effect of the antioxidant RV on these changes. In our study, we aimed to evaluate the effect of RV on the organic damage of the intestinal mucosa and liver caused by obstructive jaundice and to demonstrate the effect using IMA, an accepted marker of oxidative stress.

\section{MATERIAL AND METHODS}

This study was approved by the Local Research Ethics Committee for Experimental Animals. Twenty-four 3-month-old Wistar albino rats weighing between 250 and $300 \mathrm{~g}$ were used in our study. All the animals were kept at a constant room temperature at $22 \pm 2^{\circ} \mathrm{C}$ in a 12-hour day/night cycle. They were fed with standardised commercial rat food, including $21 \%$ protein, and provided with fresh tap water. Anaesthesia was implemented by intraperitoneal application of ketamine (Ketalar; Pfizer, İstanbul, Turkey) $50 \mathrm{mg} / \mathrm{kg}$ and xylazine $10 \mathrm{mg} / \mathrm{kg}$ (Rompun; Bayer, İstanbul, Turkey).

In the sham group (Group 1, $n=8$ ), the hepatic pedicule was found under the liver by retracting the duodenum after making an abdominal incision. The exploration was completed by exposing the common bile duct, and the abdomen was closed. The rats were fed standard food and tap water for 14 days. At the end of this period, they were sacrificed by high-dose anaesthesia after blood and fullthickness terminal ileum sampling.

In the control group (Group 2, $\mathrm{n}=8$ ), the common bile duct was ligated and divided. The abdomen was then closed, and the animals were fed standard food and tap water. Additionally, isotonic serum $(0.9 \% \mathrm{NaCl})$ identical in volume to the RV in Group 3 was injected intraperitoneally for 14 days. At the end of this period, the rats were sacrificed after blood and tissue sampling.

In the study group (Group 3, n=8), the same procedures as in Group 2 were applied, with the exception of the intraperitoneal RV $(10 \mathrm{mg} / \mathrm{kg} / \mathrm{day})$ injection for 14 days. At the end of this period, the rats were sacrificed after blood and tissue sampling. The sera obtained were immediately centrifuged (10 min at $3000 \mathrm{~g}$ ), and whole blood samples were stored at $-80^{\circ} \mathrm{C}$ until testing.

\section{Evaluation of small bowel mucosal villi}

The small bowel was placed in $10 \%$ formalin. Four samples were taken from different points of the specimens and embedded in one paraffin block. Two serial sections ( $5 \mu \mathrm{m}$ thickness) were cut from each block, and these were deparaffinised, stained with haematoxylin-eosin, and assessed under the microscope. Using an ocular micrometer, the diameters of 10 villi were measured randomly in each field, and their average was used for statistical analysis.

\section{Alanine aminotransferase and aspartate aminotransferase study}

The sera were warmed to room temperature and tested with a kit obtained from Randox laboratory Ltd, (Antrim, Northern Ireland, UK) in an autoanalyser (ABBOTT Architect/C 16000 autoanalyser, IL, USA). The results were recorded as IU/L.

\section{Ischaemia-modified albumin study}

The sera were warmed to room temperature and then tested with a BIOSOURCE Elisa kit (MBS702713 IMA RAT KIT - San Diego, CA USA) in a DSX Four-Plate Automated ELISA Processing System (NC, USA) device by the ELISA method. The results were recorded as $\mathrm{mg} / \mathrm{dL}$.

\section{Statistical analysis}

Data were analysed using IBM SPSS Statistics, version 20.0 (SPSS Inc., Chicago, IL, USA). Kolmogorov-Smirnov tests were used to test the normality of data distribution. Data are expressed as the mean value \pm standard deviation (SD) and median (25-75\% percentiles). Comparison of variables between groups was performed using one-way analysis of variance (ANOVA), Holm-Sidak Multiple Comparison Test, Kruskal-Wallis test, or Tukey's Multiple Comparison Test. P values are given with the standard deviation and values under 0.05 were accepted as significant.

\section{RESULTS}

The villus thickness of the small bowel, serum total bilirubin, alanine aminotransferase (ALT), aspartate aminotransferase (AST), and IMA concentrations were measured and compared between the groups (Table 1). Group 2 showed significant thickening and blunting (due to edema) of small bowel mucosal villi compared with Group $1(\mathrm{p}=0.001)$ (Table 1, Figures 1 and 2). In addition, inflammation was more prominent in Group 2. In Group 3, the villus thickness was significantly decreased compared with Group $2(\mathrm{p}=0.014)$. No structural change was observed in the tunicae muscularis and serosa among the groups.

Total bilirubin levels in Group 2 were significantly higher than those in Group $1(\mathrm{p}<0.001)$. Although there was a nonsignificant decrease in bilirubin levels between Group 3 and Group 2, the differences between the values of Group 3 and Group 1 was also nonsignificant.

The AST and ALT levels in Groups 2 and 3 were significantly higher than those in Group $1(\mathrm{p}<0.001)$. Although the decrease in AST and ALT levels between Groups 2 and 3 was not significant $(\mathrm{p}=0.130)$, the difference in the ALT values of Group 3 and Group 1 was also not significant. The IMA levels of Group 2 were significantly higher than those in Group $1(\mathrm{p}<0.001)$. The IMA levels of Group 3 were significantly lower than those of Group $2(\mathrm{p}=0.0013)$ (Table 1, Figure 3).

\section{DISCUSSION}

Wang et al. (20) detected partial or subtotal villus atrophy (shortening and widening of villi) in the small bowel, subepithelial edema, and lymphocyte/neutrophil elevation in the lamina propria after experimental extrahepatic cholestasis. In addition, they showed that these events decreased following the administration of ethyl pyruvate, which is known to have 
TABLE 1. Alanine aminotransferase, aspartate aminotransferase, ischaemia-modified albumin, and villus diameter values and statistical analysis of the groups

\begin{tabular}{|c|c|c|c|c|}
\hline & $\begin{array}{c}\text { Group } 1 \\
(n=8)\end{array}$ & $\begin{array}{c}\text { Group } 2 \\
(n=8)\end{array}$ & $\begin{array}{c}\text { Group } 3 \\
(n=8)\end{array}$ & Statistics and $\mathrm{p}$ \\
\hline Total bilirubin & 0.1 & 18.35 & 11.55 & $\mathrm{H}=21.26$ \\
\hline [median $(25-75 \%$ percentile $)]$ & $(0.1-0.1)$ & $(15.25-20.7)$ & $(10.85-12.30)$ & $\mathrm{p}<0.001^{*}$ \\
\hline AST & 148.5 & 148.5 & 472.50 & $\mathrm{H}=17.79$ \\
\hline [median $(25-75 \%$ percentile $))$ & $(111.5-187.0)$ & $(602.0-1116.0)$ & $(390.5-654.0)$ & $\mathrm{p}<0.001^{¥, \S}$ \\
\hline ALT & 53.0 & 120.0 & 89.5 & $\mathrm{H}=11.95$ \\
\hline [median $(25-75 \%$ percentile $)]$ & $(44.5-58.0)$ & $(93.0-159.0)$ & $(81.5-104.0)$ & $\mathrm{p}=0.003^{¥}$ \\
\hline IMA & $0.113 \pm 0.009$ & $0.138 \pm 0.016$ & $0.117 \pm 0.006$ & $\mathrm{~F}=11.38$ \\
\hline$($ mean $\pm \mathrm{SD})$ & & & & $\mathrm{p}<0.001^{¥, \S, £}$ \\
\hline Villus diameter & $92.19 \pm 13.26$ & $145.31 \pm 35.32$ & $109.37 \pm 12.94$ & $\mathrm{~F}=11.09$ \\
\hline$($ mean $\pm \mathrm{SD})$ & & & & $\mathrm{p}=0.001^{¥, \mathrm{f}}$ \\
\hline
\end{tabular}

${ }^{\ddagger} \mathrm{p}<0.05$ for Group 1 and Group $2 ;{ }^{8} \mathrm{p}<0.05$ for Group 1 and Group $3 ;{ }^{\mathrm{f}} \mathrm{p}<0.05$ for Group 2 and Group 3.

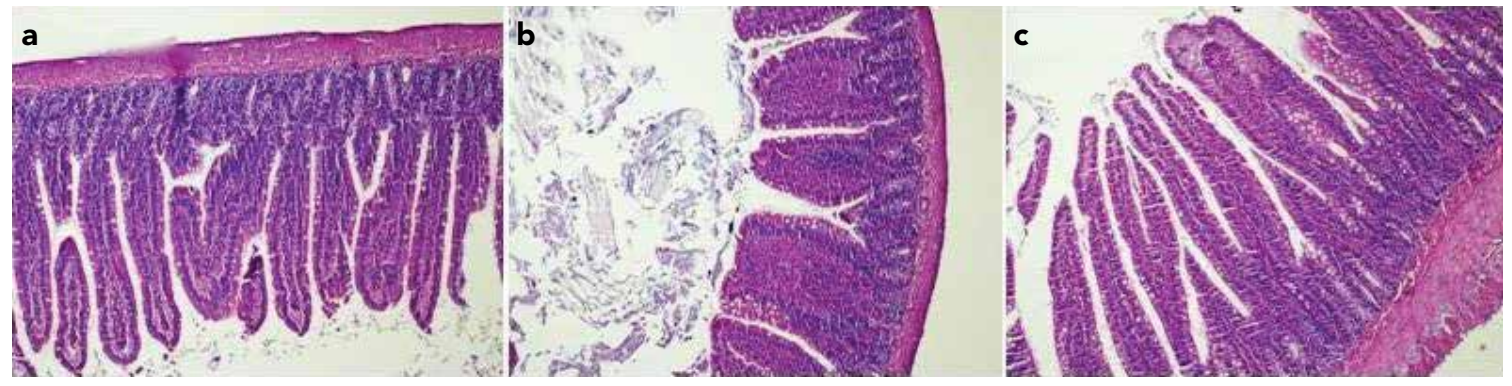

FIG. 1. a-c. Microscopic appearance of small bowel walls. Group 1: normal villus structure of the small bowel mucosa. Group 2: significant thickening and blunting of mucosal villi. Group 3: similar appearance to Group 1, with a normal villus structure $(\mathrm{HE} \times 40)$

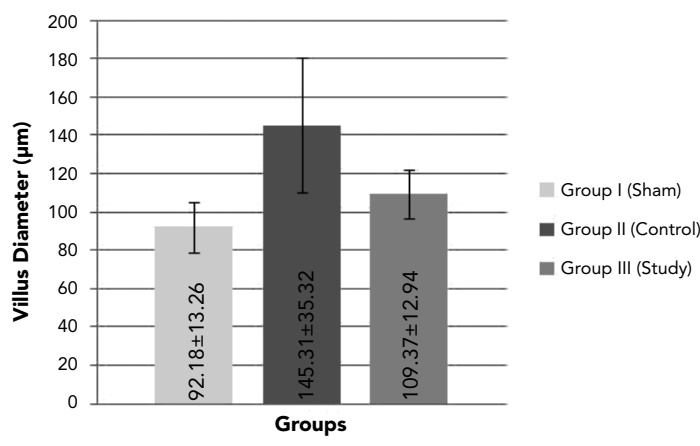

FIG. 2. Mean villus diameters of the groups are shown in a bar graph with lines indicating standard deviations

antioxidant properties. In our study, the diameters of the villi in the small bowel were significantly increased following obstructive jaundice (Group 2). The thicknesses of the villi and their structure approximated those of the control group after this increase was significantly lowered by RV administration (Group 3) (Figures 1 and 2). Our findings suggest that RV administration reduces the pathological changes of the bowel mucosa in the extrahepatic cholestasis model. We estimate that this effect would contribute to decreased bacterial translocation and systemic outcomes in inflammation.

Bile salts that cannot flow toward the duodenum due to obstruction have a detergent effect on the liver, and cause oxidative damage and cell death. Neutrophils and macrophages are activated by the increase in FORs in the surrounding environment, and the resulting pathophysiological chain of events results in increased levels of inflammatory cytokines. Cholangiocytes may also secrete proinflammatory cytokines, such as tumour necrosis factor (TNF)-alpha and interleukin (IL)-6. Experimental studies reported that these circulating cytokines increased the production of FORs. For example, studies reported that TNF-alpha caused oxidative stress by increasing the production of superoxide, hydroxyl, and hydrogen peroxide molecules $(21,22)$. In case of a persistent obstruction, elevated bilirubin accumulates in other parts of the body. Oxidative damage then begins to develop as a result of insufficient functioning of glutathione (the most important component of the cellular antioxidant system) and other antioxidative systems, and peroxidation of membrane phospholipids is induced by the elevated free radicals $(7,23)$.

In biliary obstruction, the liver is the first organ to be affected. The damage of liver tissue can be followed by changes 


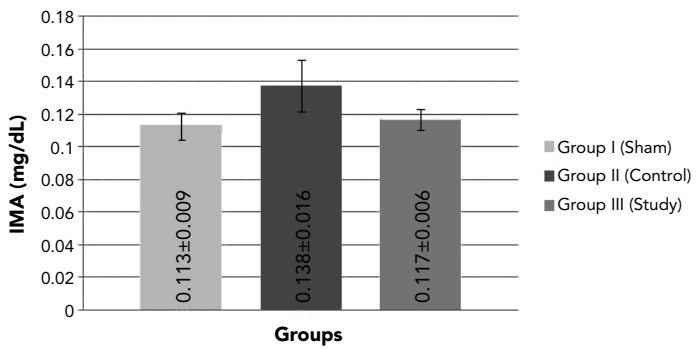

FIG. 3. Mean IMA values of the groups are shown in a bar graph with lines indicating standard deviations

in serum ALT and AST values. In studies by Ara et al. (24) and Kirimlioglu et al. (25), oxidative damage increased as a result of experimental extrahepatic cholestasis (choledoc ligation) in rats and caused cellular damage. They also found that bilirubin and liver enzymes in an RV-treated group were lower than those in an RV-free control group. Another study showed in vitro that RV protected hepatic cells from oxidative damage (26). In our study, bilirubin, AST, and ALT levels in the control (2) group were significantly higher than those in the sham (1) group, as expected. Although there were obvious differences between the control (2) and study (3) groups, these were not statistically significant, probably because of the limited number of subjects (Table 1). With regard to the proximity of the values between sham (1) and study (3) groups, with a nonsignificant difference, it is logical to conclude that our findings of decreased liver injury in RV-administered rats are consistent with the data in the literature. The change in bilirubin levels may be due to decreased erythrocyte haemolysis, which is known to develop in obstructive jaundice, as a result of the oxidative stress-reducing effect of RV (27).

Many studies have shown that IMA is an early marker of acute ischemic conditions within the organism. Sinha et al. (28) reported that IMA might be used for the early diagnosis of acute coronary syndrome. In another study, Valle Gottlieb et al. (29) found significantly higher IMA values in patients with metabolic syndrome compared with a control group. Mentese et al. (30) reported that IMA was an appropriate ischaemiareperfusion injury marker of testicular damage during acute and chronic periods. In addition, IMA was reported to be an important indicator of liver function (10). We also observed that the antioxidant RV attenuated IMA levels in parallel with changes in liver enzymes and bilirubin. We believe that the determinative potential of IMA for oxidative stress is remarkable and can be investigated in further laboratory and even clinical studies.

In conclusion, in addition to RV having a potentially positive effect on oxidative stress in the liver associated with obstructive jaundice, it also attenuated small bowel mucosal changes in this experimental model. We suggest that the known potent antioxidant and anti-inflammatory characteristics of RV might be an appropriate field for future studies on obstructive jaundice.

Ethics Committee Approval: Ethics committee approval was received for this study.

Informed Consent: N/A

Peer-review: Externally peer-reviewed.

Author contributions: Concept - V.T., E.O.; Design - V.T., E.O., Y.G., M.Ç.; Supervision - E.O.; Resource - V.T., T.Ş., A.G., U.B.; Materials - V.T., T.Ş., A.G., M.Ç., U.B.; Data Collection\&/or Processing - V.T., T.Ş., A.G., U.B.; Analysis\&/ or Interpretation - V.T., E.O., Y.G., M.Ç., N.E., C.B.; Literature Search - V.T., E.O.; Writing - V.T., E.O., Y.G., M.Ç.; Critical Reviews - E.O.

Acknowledgements: The authors would like to thank to Prof. Nilay Etiler and Assoc. Prof. Canan Baydemir for their assistance during the statistical assessment process.

Conflict of Interest: No conflict of interest was declared by the authors.

Financial Disclosure: This Project is financially supported by Kocaeli University Scientific Research Projects Coordination Unit (Project No: 2011/11 HDP)

\section{REFERENCES}

1. Gonzalez-Correa JA, De La Cruz JP, Martin-Aurioles E, Lopez-Egea MA, Ortiz P, Sanchez de la Cuesta F. Effects of S-adenosyl-L-methionine on hepatic and renal oxidative stress in an experimental model of acute biliary obstruction in rats. Hepatology 1997;26:121-7. [CrossRef]

2. Singh S, Shackleton G, Ah-Sing E, Chakraborty J, Bailey ME. Antioxidant defenses in the bile duct-ligated rat. Gastroenterology 1992;103:1625-9.

3. Sokol RJ, Devereaux M, Khandwala RA. Effect of dietary lipid and vitamin $\mathrm{E}$ on mitochondrial lipid peroxidation and hepatic injury in the bile duct-ligated rat. J Lipid Res 1991;32:1349-57.

4. Cantürk NZ, Canturk Z, Utkan NZ, Yenisey C, Ozbilim G, Yildirir C, et al. Cytoprotective effects of alpha tocopherol against liver injury induced by extrahepatic biliary obstruction. East Afr Med J 1998;75:77-80.

5. Yamauchim N, Kuriyama H, Watanabe N, Neda H, Maeda M, Niitsa Y. Intracelluler hydroxyl radical production induced by recombinant human tumor necrosis factor and its implication in the killing of tumor cells in vitro. Cancer Res 1989;49:1671-5.

6. Galicia-Moreno M, Favari L, Muriel P. Antifibrotic and antioxidant effects of n-acetylcysteine in an experimental cholestatic model. Eur $J$ Gastroenterol Hepatol 2012;24:179-85. [CrossRef]

7. Krahenbuhl S, Talos C, Lauterburg BH, Reichen J. Reduced antioxidative capacity in liver mitochondria from bile duct ligated rats. Hepatology 1995;22:607-12. [CrossRef]

8. Sgambato A, Ardito R, Faraglia B, Boninsegna A, Wolf FI, Cittadini A. Resveratrol, a natural phenolic compound, inhibits cell proliferation and prevents oxidative DNA damage. Mutat Res 2001;496:171-80. [CrossRef]

9. Burkitt MJ, Duncan J. Effects of trans-resveratrol on copper-dependent hydroxyl-radical formation and DNA damage: evidence for hydroxylradical scavenging and a novel, glutathione-sparing mechanism of action. Arch Biochem Biophys 2000;381:253-63. [CrossRef]

10. Chen CY, Tsai WL, Lin PJ, Shiesh SC. The value of serum ischemiamodified albumin for assessing liver function in patients with chronic liver disease. Clin Chem Lab Med 2011;49:1817-21. [CrossRef] 
11. Bar-Or D, Lau E, Winkler JV. A novel assay for cobalt-albumin binding and its potential as a marker for myocardial ischemia-a preliminary report. J Emerg Med 2000;19:311-5. [CrossRef]

12. Sharma R, Gaze DC, Pellerin D, Mehta RL, Gregson H, Streather CP, et al. Evaluation of ischaemia-modified albumin as a marker of myocardial ischaemia in end-stage renal disease. Clin Sci (Lond) 2007;113:25-32. [CrossRef]

13. Chan B, Dodsworth N, Woodrow J, Tucker A, Haris R. Site-specific N-terminal auto-degradation of human serum albumin. Eur J Biochem 1995;227:524-8. [CrossRef]

14. Parks RW, Stuart Cameron CH, Gannon CD, Pope C, Diamond T, Rowlands BJ. Changes in gastrointestinal morphology associated with obstructive jaundice. Pathol 2000;192:526-32. [Cross Ref]

15. Assimakopoulos SF, Thomopoulos KC, Patsoukis N, Georgiou CD, Scopa $\mathrm{CD}$, Nikolopoulou VN, et al. Evidence for intestinal oxidative stress in patients with obstructive jaundice. Eur J Clin Invest 2006;36:181-7. [CrossRef]

16. Kuzu MA, Kale IT, Cöl C, Tekeli A, Tanik A, Köksoy C. Obstructive jaundice promotes bacterial translocation in humans. Hepatogastroenterology 1999;46:2159-64.

17. Fouts DE, Torralba M, Nelson KE, Brenner DA, Schnabl B. Bacterial translocation and changes in the intestinal microbiome in mouse models of liver disease. J Hepatol 2012;56:1283-92. [CrossRef]

18. Assimakopoulos SF, Tsamandas AC, Louvros E, Vagianos CE, Nikolopoulou VN, Thomopoulos $\mathrm{KC}$, et al. Intestinal epithelial cell proliferation, apoptosis and expression of tight junction proteins in patients with obstructive jaundice. Eur J Clin Invest 2011;41:117-25. [CrossRef]

19. Bemelmans MH, Gouma DJ, Greve JW, Buurman WA. Cytokines tumor necrosis factor and interleukin- 6 in experimental biliary obstruction in mice. Hepatology 1992;15:1132-6. [CrossRef]

20. Wang P, Gong G, Wei Z, Li Y. Ethyl pyruvate prevents intestinal inflammatory response and oxidative stress in a rat model of extrahepatic cholestasis. J Surg Res 2010;160:228-35. [CrossRef]

21. Liu TZ, Lee KT, Chern CL, Cheng JT, Stern A, Tsai LY. Free radicaltriggered hepatic injury of experimental obstructive jaundice of rats in- volves overproduction of proinflamatory cytokines and enhanced activation of nuclear factor kappaB. Ann Clin Lab Sci 2001;31:383-90.

22. Hennet T, Richter C, Peterhans E. Tumour necrosis factor-alpha induces superoxide anion generation in mithocondria of L929 cells. Biochem J 1993;289:587-92.

23. Pastor A, Collado PS, Almar M, Gonzalez-Gallego J. Antioxidant enzyme status in biliary obstructed rats:effects of N-acetylcysteine. J Hepatol 1997;27:363-70. [CrossRef]

24. Ara C, Kirimlioglu H, Karabulut AB, Coban S, Ay S, Harputluoglu M, et al. Protective effect of resveratrol against oxidative stress in cholestasis. J Surg Res 2005;127:112-7. [CrossRef]

25. Kirimlioglu V, Ara C, Yilmaz M, Ozgor D, Isik B, Sogutlu G, et al. Resveratrol, a red wine constituent polyphenol, protects gastric tissue against the oxidative stress in cholestatic rats. Dig Dis Sci 2006;51:298302. [CrossRef]

26. Rubiolo JA, Mithieux G, Vega FV. Resveratrol protects primary rat hepatocytes against oxidative stress damage: activation of the Nrf2 transcription factor and augmented activities of antioxidant enzymes. Eur $J$ Pharmacol 2008;591:66-72. [CrossRef]

27. Stillman AE, Giordano GF. Spur cell anemia associated with extrahepatic biliary tract obstruction. Am J Gastroenterol 1983;78:589-92.

28. Sinha MK, Roy D, Gaze DC, Collinson PO, Kaski JC. Role of "ischemia modified albumin," a new biochemical marker of myocardial ischaemia, in the early diagnosis of acute coronary syndromes. Emerg Med $J$ 2004;21:29-34. [CrossRef]

29. Valle Gottlieb MG, da Cruz IB, Duarte MM, Moresco RN, Wiehe M, Schwanke $\mathrm{CH}$, et al. Associations among metabolic syndrome, ischemia, inflammatory, oxidatives, and lipids biomarkers. J Clin Endocrinol Metab 2010;95:586-91. [CrossRef]

30. Mentese A, Turkmen S, Karaguzel E, Karaca Y, Tatli O, Sumer AU, et al. The predictive value of ischemia-modified albumin in long-term results of ischemia-reperfusion injury in an experimental testicular torsion model. Urology 2012;80:689-94. [CrossRef] 